\title{
Digitalization of Environmental Monitoring as an Enabler of Circular Economy Transition
}

\author{
Wegner-Kozlova E.O. ${ }^{1,2, *}$ Guman O.M. ${ }^{3}$
}

\author{
${ }^{1}$ Institute of Economics The Ural Branch of Russian Academy of Science, Russian Federation \\ ${ }^{2}$ Federal State Autonomous Educational Institution of Higher Education «Ural Federal University named after the first \\ President of Russia B.N. Yeltsin», Russian Federation \\ ${ }^{3}$ Ural State Mining University, Russian Federation \\ *Corresponding author. Email: katya.human@mail.ru
}

\begin{abstract}
The vital task of reconciling economic interests with the preservation of ecosystem's natural balance brings about topical issues related to sustainable development. Global scientific community considers the transition from a linear to a circular economy (CE) to be one of the ways of overcoming this situation. In this regard, the issues of applying the Internet of things (IoT) technology, intensive data exchange, and predicative analytics to the economic interaction based on a circular model are of particular importance. The issues of circular economy transition by applying digital technologies have not yet been fully covered in the scientific literature, which allows for setting the following tasks: first, to define the essence of circular economy digitalization, and, secondly, to organize theoretical and practical information related to the digitalization of environmental monitoring, considering it as a circular economy enabler.
\end{abstract}

Keywords: circular economy, digital monitoring of the environment

\section{INTRODUCTION}

The vital task of reconciling economic interests with the preservation of ecosystem's natural balance brings about topical issues related to sustainable development. On the one hand, the effectiveness of Russia's integration into the world economy is determined by the level of competitiveness of its markets. Here the development of high-tech sectors of the economy becomes one of the key factors for improving markets performance, which at first glance does not imply prioritizing the task of maintaining ecological well-being.

On the other hand, there is a need for transition towards a more stable sociotechnical system. Environmental issues, biodiversity loss as well as water, air and soil contamination, resource depletion and excessive land use are increasingly threatening the Earth's life support systems [5]. It is obvious that the degradation of ecological systems has a negative impact on economic indicators, as it reduces the quality of both natural and human resources. It should be noted that the goals of achieving sustainable development are relevant not only for Russia but also for the whole world, which is demonstrated by the $2030 \mathrm{UN}$ Agenda for Sustainable Development.

Global scientific community considers the concept of circular economy (CE), which is being actively implemented in Japan, China, Germany and other EU countries to be one of the ways of overcoming the existing situation. CE is seen as a "new worldview", a "new way of industrialization" or an approach that requires a change in the global paradigm of production [12]. Until quite

recently, the evolution of production activities was considered within the framework of a universal linear model of resource consumption, which implies: resource collection and extraction $\rightarrow$ product manufacturing $\rightarrow$ product delivery to customer $\rightarrow$ product disposal. However, the need to reconcile economic development and environmental compliance has turned our attention to a nonlinear model, meaning "circularity" of economy or "circular economy" that allows combining economic growth with environmental responsibility. In this regard, the issues of applying the Internet of things (IoT) technology, intensive data exchange, and predicative analytics to the economic interaction based on a circular model are of particular importance.

\section{METHODOLOGY}

Circular economy transition cannot but be accompanied by active interdisciplinary interaction. On the one hand, the tasks set by the circular economy invoke general scientific methods: deductive and inductive reasoning, including hypothetical and deductive method, analysis and synthesis, institutional analysis as well as statistical, comparative and causal analysis, factor analysis, analogy method, historical 
method that allows taking into account the historical, social and cultural specifics of the economy, and other general theoretical methods. On the other hand, they require specific knowledge of ecological processes. Specific methods related to the subject under study include working with data from geoecological, hydrogeological, landscape-geochemical, engineering-geological surveys as well as analytical experimental work in laboratory and field. Methods of physical and numerical modeling with GIS and laboratory analytical studies are required as well.

\section{RESULTS}

\subsection{Digitalization opportunities for the circular economy}

Today, one of the generally accepted disadvantages of the circular economy is the lack of both conceptual clarity and a single definition of this concept [13]. CE non-linearity implies a "circularity" of economy or "circular economy" that allows combining economic growth with environmental responsibility. According to Ellen MacArthur, the circular economy is an industrial system, which is restorative and regenerative by design. It replaces the concept of finite resources with the restoration, shifts towards renewable energy sources, eliminates the use of hazardous chemical substance that hamper recycling process, and aims at better waste management through ideal design of materials, products, systems, and business models [3]. Circular economy model is based on the principles of sustainable development, the main tools of which are environmental innovations and green technologies, i.e. environmentally friendly technologies [10]. Circular economy transition requires significant changes in designing, producing, consuming, using, disposing and reusing waste. The main task of the $\mathrm{CE}$ is to maximize the life cycle of valuable materials.

Therefore, we can assume that circular economy digitalization is a process:

1. Allowing us to receive and exchange significant and detailed information, which ensures the interaction of all the parties concerned (state, regional and local authorities, population, scientific community, business community, etc.);

2. Implying the use of digital technologies to introduce innovations in the business model, in order to generate new revenue, create added value and enhance the ecosystem's stability.

Digitalization provides ample opportunities for the circular economy development. In particular, within the circular economy transition, digitalization allows [6]:

1. Improving project activities.

2. Improving the efficiency of information activities, and thus attracting target segments of stakeholders.
3. Product monitoring and tracking, which minimizes the risk of misusing the product and allows multiple users to share it, thereby extending its life cycle and increasing its performance efficiency.

4. Improving technical service.

5. Providing preventive and predictive maintenance.

6. Optimizing product performance and increasing resource efficiency.

7. Improving product quality and performance efficiency as well as extending its life cycle.

8. Propelling reconstruction, restoration and recycling activities.

\subsection{Digitalization of environmental monitoring}

One of the main principles of the circular economy, which is part of the $3 \mathrm{R}$ basic framework, is the Principle of Reduce, which involves reducing both the consumption of natural resources and materials and the negative impact on the environment. The impact on the ecosystem is controlled through monitoring.

The purpose of environmental monitoring is to identify trends in the development and change of environmental components (atmosphere, soil, subsoil, surface and groundwater), taking into account their environmental consequences for humans and other organisms within the designed (or existing) facilities and adjacent territories, as well as to develop recommendations and management solutions to optimize facility performance, ensure environmentally friendly conditions for its existence and sustainable development [8].

Today, the most relevant and promising way of environmental monitoring is the one carried out with the application of modern information technologies, including the Internet of things (IoT) systems, which allows collecting and analyzing data about the environment and preventing environmental accidents and catastrophes.

Environmental monitoring functions:

- Environmental quality assessment

- Environmental impact assessment

- Information base for environmental management and decision-making

- Environmental efficiency analysis

- Environmental emergency response.

Environmental monitoring stages:

1. To conduct a preliminary survey in order to determine the main components of the natural environment that need monitoring; to determine the framework of observed indicators; to measure the base values.

2. To create a continuous environmental monitoring system; to provide relevant equipment and performance support.

3. To conduct on-site observation with the aim of determining trends in environmental indicators.

4. To conduct environmental monitoring and modeling; to make short- and long-term forecasts; to provide recommendations. 
Several problems related to conducting local (on-site) environmental monitoring have been identified based on the experience in environmental monitoring projects [7]:

- The problem of the program-targeted approach.

- $\quad$ The problem of optimum monitoring scope.

- Monitoring complexity.

- On-site observation frequency.

- The problem of determining the base values of environmental components under technogenically altered conditions.

- The problem of choosing observation station locations.

- The problem of providing monitoring methodology.

- The problem of processing environmental monitoring data throughout the observation period. Processing should be based on a single information technology widely using geographic information system (GIS) equipment, as well as interactive technologies in a common computing environment.

- The problem of forecasting: the monitoring system should monitor the current state of environmental components, as well as to conduct retrospective analysis and forecasting based on mathematical modeling.

Environmental information systems (EISs) serve to collect, store, process, and reproduce spatial, temporal, and intentional environmental data and information. They consist of different environmental data banks with different environmental information that facilitates problem-oriented and goal-oriented access to the information. They are an important auxiliary tool for depicting the actual state of the environment. As a planning and monitoring tool, they can help to account for environmental changes in real-time mode and to provide for early damage detection. From the user's point of view, EISs facilitate environmental issues processing and public informing [11].

Main features of environmental information systems [11]:

- EISs cover the environment as a whole or its parts.

- $\quad$ EISs have a systematic structure.

- $\quad$ EISs have a spatial component (GIS).

- EISs serve both for operating and planning.

- EISs are human/computer systems.

- $\quad$ EISs are not a uniform tool.

- EISs facilitate access to information through meta-information systems.

Environmental information system comprises three levels that differ in the methods of environmental information processing [14]:

- Expert assessment module. Decision making support

- $\quad$ GIS module. Comprehensive systems analysis of the environment state

- Database management system module. Monitoring results storage and processing.
At the lower level of EIS, standard (or customized) database management systems (DBMS) are used to store and protect source data on the state of the environment and its primary statistical processing (basic statistics methods). DBMS can be exemplified by personal DBMS - MS Access, MS FoxPro (file/server technology), or industrial DBMS, such as MS SQL-server, Oracle (client/server technology). Customized DBMSs are usually created either by configuring an existing standard DBMS, or by creating their own software application that provides solutions to one-dimensional applied problems and is as friendly as possible for the end-user. In both cases, it will be necessary to create a branched structure of a relational database. At the middle level of EIS, geographic information systems (GIS) are used to analyze information on the state of the environment. GIS can be illustrated by the most common software products, such as GS Surfer, ArcView, MapInfo, AutoCad, etc. External software products, such as MS Graph, MS Excel, MathCAD, Statistica, etc., can be used for in-depth statistical information processing. Such systems provide comprehensive processing, analysis and visualization of spatially distributed information, allowing for systematizing the output of cartographic ecoinformational basis for natural resource management based on the experience accumulated by specialists in this field. A variety of software products are used for 3D geological filtration modeling, geological migration modeling, numerical modeling of filtration and miscible liquids migration, including MODFLOW, Mt3DMS, AquaChem, PHREEQC, HydroGeo, SEAWAT-2000, DENSFLOW, etc. [1], [9], [15].

Practical implementation of digital environmental monitoring in the Russian Federation is obstructed by a number of objective organizational and legal reasons.

Currently, the legislation of the Russian Federation allows using automated monitoring tools only for the category I facilities. According to the Federal Law as of 21.07.2014 No. 219-FZ, it is mandatory to provide stationary sources with automatic equipment measuring and accounting for emissions/discharges of pollutants and their concentration as well as technical equipment of recording and transmitting information if they are located at the category I facilities. The category I facilities include those that have a significant negative impact on the environment and are related to the areas of application of the best technologies available. In addition, industrial facilities that have a negative impact on the environment are divided into:

- Category II facilities that have a moderate negative impact on the environment

- Category III facilities that have a minor negative impact on the environment

- Category IV facilities that have a minimal negative impact on the environment.

Thus, the Russian Federation does not legislate the need for automated monitoring for the category II-IV facilities. According to the Government Decree as of 13 March 2019 No. 262, the creation of an automatic control system is aimed at solving the following tasks: 


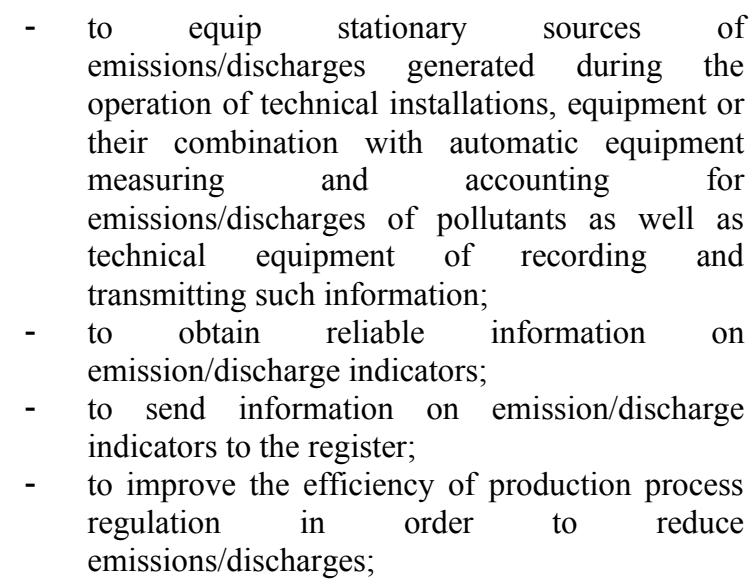

\section{CONCLUSION}

The basic principle of the circular economy - the Principle of Reduce - implies, among other things, that the negative impact on the ecological system is to be decreased. Environmental monitoring performed with advanced information technology allows us to respond effectively and promptly to environmental security threats. Economic development creates great pressure on territorial ecosystems and the environment. Economic benefits that usually come with the establishment and operation of large-scale manufacturing facilities result in ecosystem degradation and have a negative impact on surface water, groundwater, air and soil properties. Monitoring without IoT technology faces a number of exploitation challenges including low levels of automation, inefficient operating costs, and lack of spatial and temporal coverage. IoT technology development enhances environmental data collection and analysis. Information control over ecosystem changes helps to efficiently adapt to shifting parameters and address risks to environmental safety at an early stage. Digital monitoring permits to track, gather and aggregate detailed high-quality environmental information with high accuracy, as well as to dynamically monitor and exchange information in real time.

For the development of digital monitoring in Russia, the following actions should be proposed as legal and organizational recommendations:

1. Legally fix the necessity to equip stationary sources with automated devices for measuring and recording pollutant emissions/discharges and concentration of pollutants, as well as with technical means of information gathering and distribution. This is compulsory for categories I -IV facilities.

2. Expand the list of automatically controlled indicators to the list of pollutants which are subject to State regulatory measures.
- to conduct state environmental supervision over the fulfillment of the conditions stipulated by the integrated environmental permit.

This document sets out an exhaustive list of indicators that are subject to automatic control. However, in practice, the list of pollutants that are subject to state regulation is much longer: atmospheric air -254 indicators, water -249 indicators, soil -63 indicators. The legislation does not provide for considering the enterprise profile during monitoring, so it is not done in practice.

Also, there are currently no incentive programs for digital monitoring in the Russian Federation. The high cost of this system is due to the need for methodological support, purchase, installation and maintenance of monitoring devices and sensors, as well as the necessity of ensuring the transmission and processing of the received data, and professional staff training.

3. Adopt legislatively the importance of taking into account regional aspects of the natural environment and specific activities of concrete enterprises.

4. Elaborate measures of target-oriented support to enterprises encouraging the implementation and use of digital monitoring.

\section{ACKNOWLEDGMENT}

The reported study was funded by RFBR, project number 20-010-00558.

\section{REFERENCES}

[1] Bukaty M.B.. Software development for solving hydrogeological problems. // News of Tomsk Polytechnic University [News of TPU]. - 2002. Vol. 305, Issue No. 6: Geology, mineral exploration and survey in Siberia. - pp. 348-365.

[2] Decree of the Russian Federation Government dated 13.03.2019 No. 262 "On approval of the Rules for creation and operation of the system for automatic control of pollutant emission and (or) contaminant release". Official website of legal information http://www.pravo.gov.ru, 15.03.2019, "Official gazette of the Russian Federation", 18.03.2019, No. 11, Art. 1146.

[3] Ellen MacArthur Foundation Towards the Circular Economy: Economic and Business Rationale for an Accelerated

Transitionhttps://www.ellenmacarthurfoundation.org/as sets/downloads/publications/Ellen-MacArthur-

Foundation-Towards-the-Circular-Economy-vol.1.pdf P.7 
[12] Reike D., Vermeulen W.J.V., Witjes S. The circular economy: New or Refurbished as CE 3.0? Exploring Controversies in the Conceptualization of the Circular Economy through a Focus on History and Resource Value Retention Options // Resources, Conservation \& Recycling 135 (2018) P. 246-264.

[5] Geissdoerfer M., Savaget P., Bocken N.M.P., Hultink E.J. The Circular Economy - A new sustainability paradigm? // Journal of Cleaner Production 143 (2017) P. 757-768

[6] Grebenkin A.B., Wegner-Kozlova E.O., Opportunities and risks of circular economy digitalization / / Digital transformation of industry: trends, management, strategies: Proceedings of the First International Research and Practical Conference, Yekaterinburg, October 11, 2019 - Yekaterinburg: Institute of Economics, Ural Branch of the Russian Academy of Sciences, 2019. pp. 138-146

[7] Gryaznov O.N., Guman O.M., Dolinina I.A.. Local environmental monitoring issues // Environmental Safety of the Urals: Proceedings of Research and Practical Conference, Ekaterinburg, 2002. P. 152.

[8] Guman O.M.. Peculiarities of local environmental monitoring of mining and industrial facilities: the case of the Middle Urals / O.M. Guman O., A.V. Zakharov, A.B. Makarov / / News of Higher Educational Institutions. Mining Journal. - 2007. No. 2. - pp. 56-59

[9] Kvachev V.N., Kvacheva E.V., Sergeev S.V.. Methodological and technological aspects of automation of creating 3D geological filtration models when solving geoecological problems. Modeling for solving geoecological problems. Issue 11. Proceedings of the Annual Session of the Scientific Council of the Russian Academy of Sciences on the Issues of Geoecology, Geological Engineering and Hydrogeology (March 23-24, 2009) - Moscow: GEOS, 2009, pp. 114-118.

[10] Modern Economic Problems / M.M. Brutyan, M.P. Vakhrameeva, T.M. Vorozheykina et alia / General editor: S.S. Chernova - Novosibirsk: CRNS Publishing house, 2016. P. 12

[11] Project: Implementation of environmental principles in the Russian land-use planning (EcoRus). Complex 3/6 - Recommendation No. 4: Territory monitoring and territorial information systems in Germany; Findings for Russian land-use planning. Electronic resource. Access mode https://www.ioer.de/fileadmin/internet/IOER_Projekte/ EkoRuss/EkoRus_4.HR_Umweltmonitoring_ru.pdf
[13] Silvestri F., Spigarelli F., Tassinari M. Regional development of Circular Economy in the European Union: A multidimensional analysis // Journal of Cleaner Production 255 (2020) 120218.

[14] Zakharov A.V.. Environmental technogenesis and Asbest industrial hub monitoring (the Middle Urals). Extended Abstract of Candidate's Dissertation in Geology and Mineralogy Ekaterinburg, 2008.

[15] Zlobina V.L., Medovar Yu.A., Application of GIS in groundwater quality assessment. Modeling for solving geoecological problems. Issue 11. Proceedings of the Annual Session of the Scientific Council of the Russian Academy of Sciences on the Issues of Geoecology, Geological Engineering and Hydrogeology (March 23-24, 2009) - Moscow: GEOS, 2009, pp. 30-32. 